Western University

Scholarship@Western

Aboriginal Policy Research Consortium International (APRCi)

2002

\title{
Aboriginal Alternative Dispute Resolution in Canada - A Case Study
}

Jonathan Rudin

Follow this and additional works at: https://ir.lib.uwo.ca/aprci

Part of the Public Administration Commons

Citation of this paper:

Rudin, Jonathan, "Aboriginal Alternative Dispute Resolution in Canada - A Case Study" (2002). Aboriginal Policy Research Consortium International (APRCi). 306.

https://ir.lib.uwo.ca/aprci/306 
This article was downloaded by: [University of Western Ontario]

On: 07 December 2012, At: 07:49

Publisher: Routledge

Informa Ltd Registered in England and Wales Registered Number: 1072954 Registered office: Mortimer House, 37-41 Mortimer Street, London W1T 3J H, UK

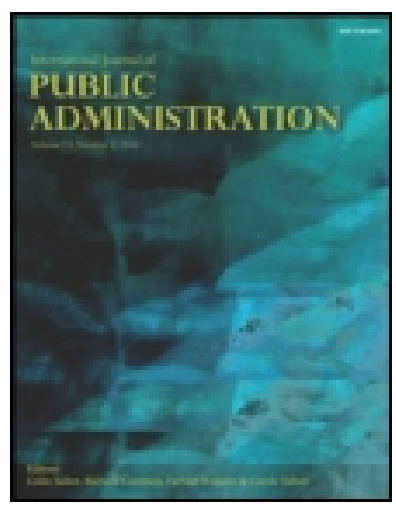

\title{
International J ournal of Public Administration
}

Publication details, including instructions for authors and subscription information: http:// www.tandfonline.com/loi/lpad20

\section{ABORIGINAL ALTERNATIVE DISPUTE RESOLUTION IN CANADA - A CASE STUDY}

\author{
Jonathan Rudin a b \\ ${ }^{a}$ Division of Social Science, York University, Toronto, Ontario, Canada \\ ${ }^{b}$ Aboriginal Legal Services, Toronto, Ontario, Canada \\ Version of record first published: 07 Feb 2007.
}

To cite this article: J onathan Rudin (2002): ABORIGINAL ALTERNATIVE DISPUTE RESOLUTION IN CANADA - A CASE STUDY, International J ournal of Public Administration, 25:11, 1403-1426

To link to this article: http:// dx. doi. org/ 10.1081/ PAD-120013352

PLEASE SCROLL DOWN FOR ARTICLE

Full terms and conditions of use: http://www.tandfonline.com/page/terms-and-conditions

This article may be used for research, teaching, and private study purposes. Any substantial or systematic reproduction, redistribution, reselling, loan, sub-licensing, systematic supply, or distribution in any form to anyone is expressly forbidden.

The publisher does not give any warranty express or implied or make any representation that the contents will be complete or accurate or up to date. The accuracy of any instructions, formulae, and drug doses should be independently verified with primary sources. The publisher shall not be liable for any loss, actions, claims, proceedings, demand, or costs or damages whatsoever or howsoever caused arising directly or indirectly in connection with or arising out of the use of this material. 
INTERNATIONAL JOURNAL OF PUBLIC ADMINISTRATION

Vol. 25, No. 11, pp. 1403-1426, 2002

\title{
ABORIGINAL ALTERNATIVE DISPUTE RESOLUTION IN CANADA - A CASE STUDY
}

\author{
Jonathan Rudin \\ Division of Social Science, York University, \\ Toronto, Ontario, Canada and Aboriginal Legal \\ Services, Toronto, Ontario, Canada \\ E-mail: jrudin@yorku.ca
}

\section{INTRODUCTION}

The 1990s saw a great upsurge of interest in Canada in the development of alternative criminal justice programs for Aboriginal ${ }^{[2]}$ people. In addition to studies, commissions and reports, funding for the creation of local alternative justice programs was made available to Aboriginal and non-Aboriginal organizations by the federal and provincial governments as well as by private foundations and by Aboriginal organizations themselves.

The purpose of this paper is two-fold. First, it seeks to put the development of these programs into context, specifically, what factors caused the interest in the development of such programs and how the structure of the Canadian criminal justice system works to allow for their development. Second, the paper looks at the development of one program in particular - the Community Council Program of Aboriginal Legal Services of Toronto - the first urban Aboriginal alternative justice program in the country. This examination will serve not only to illustrate how a program 
moves from conception to actually hearing cases, but will also look at how an alternative justice program develops a model for dealing with cases. The importance of allowing local programs to choose and develop their own models over the imposition of any one particular model will be stressed.

The paper is divided into eight sections. Following the introduction, it places the situation of Aboriginal people in Canada in a socio-economic context. The paper then looks specifically at the issue of Aboriginal overrepresentation in provincial and federal prisons. The bleak reality of overrepresentation does not, in and of itself, necessarily suggest one particular answer to this problem. Therefore, the next part of the paper examines why alternative criminal justice programs have found favour with governments, justice system personnel and Aboriginal people themselves. Following this broad, macro-level discussion, the paper focuses specifically on the development of the Community Council by Aboriginal Legal Services of Toronto (ALST). This portion of the paper examines the issues facing Aboriginal people in Canada's largest urban centre and looks at how the various stakeholders with an interest in the project were involved in its development. The paper next examines how the particular model for resolving matters before the Council was chosen and how the model has evolved over the years. The next section compares the model ultimately selected for the program with other popular models of dispute resolution. Finally, the paper draws some conclusions regarding the need for local control over the development of justice programs, particularly with respect to the choice of model for dispute resolution.

In describing the Community Council program, I am not suggesting that the approach taken in this project is the only or best way to operate an alternative justice program for Aboriginal people. All Aboriginal communities are unique and if they wish to address issues in the criminal justice field, they will do so based on the particular characteristics and needs of their community. There is no one way to deliver a culturally appropriate justice program for Aboriginal people. In the case of justice programs, imitation is not the sincerest form of flattery. What is needed is for those contemplating new programs to examine, in the broad sense, what has made particular initiatives successful and what aspects of these programs - both in terms of their development and their operation - are worthy of study and consideration in their particular circumstances.

\section{ABORIGINAL PEOPLE IN CANADA}

The Constitution Act (1982) gives explicit recognition to the rights of the Aboriginal people of Canada. S. 35(1) of the Act states: 
The existing aboriginal and treaty rights of the aboriginal peoples of Canada are hereby recognized and affirmed.

At the time s. 35(1) was enacted, there was no consensus on the meaning of the term "existing." It was not until the Supreme Court of Canada issued its 1990 decision in $R v$. Sparrow ${ }^{[3]}$ that the meaning of the term began to be fleshed out. Sparrow set out a potentially expansive notion of Aboriginal rights that the Royal Commission on Aboriginal Peoples in 1996 used to conclude that, among other things, Aboriginal people had an existing right to create their own justice systems. In subsequent decisions (R. v. van der Peet ${ }^{[4]}$ and Mitchell v. Minister of National Revenue ${ }^{[5]}$ ) the Supreme Court has restricted its concept of "existing Aboriginal rights." No court has yet ruled on whether Aboriginal people do have a right to create and operate their own justice systems, and programs developed to date have, as will be discussed, always operated within the bounds of the current criminal justice system.

Section 35 then goes to identify Aboriginal people as Indian, Inuit or Metis people. At its most basic level, Indians are those people who trace their ancestry to the indigenous tribes that occupied Canada prior to the arrival of explorers and colonists from Europe; ${ }^{[6]}$ the Inuit are the Aboriginal people of the far north - particularly the eastern part of Canada's north (previously referred to by non-Aboriginal people as Eskimos); and the Metis are those people who trace their ancestry to children born of relationships between Indian women and early fur traders and explorers, particularly from France. Over the years, the term Metis has come to be applied more generically to people of Aboriginal descent who do not have Indian status. This development is not necessarily welcomed by those who trace their ancestry to historic Metis communities and the issue of defining who is a Metis person is a very live issue today.

This brief description, does not begin to hint at the complexities surrounding the determination of who is seen as an Aboriginal person - by either or both levels of government and by Aboriginal people themselves and what particular rights such individuals might have. While this issue is complex and is the subject of on-going negotiation and litigation, it is generally not of much relevance to Aboriginal justice programs which tend to be available to all Aboriginal people.

Given the difficulties in determining who is or is not an Aboriginal person, it is not surprising that a definitive statement as to the Aboriginal population in Canada is difficult. The Royal Commission on Aboriginal Peoples (RCAP), in their very comprehensive multi-volume final report in 1996, determined the Aboriginal population to be 811,400 or $2.7 \%$ of the total population of Canada. ${ }^{[7]}$ This total consists of 624,000 
status and non-status Indians, 152,800 Metis and 42,500 Inuit. The Aboriginal population of Canada is growing faster than the general population and is younger on average than other demographic groups.

In socio-economic terms, the simplest way to look at the position of Aboriginal people is to say that if the indicator selected is one that would be desired by the general population then Aboriginal people are underrepresented; if the indicator is one that people would rather not have, the Aboriginal population is over-represented. Specifically, Aboriginal people have life spans lower than the national average, commit suicide at rates much higher than the national average, have lower incomes, lower levels of education and poorer health than non-Aboriginal people. A government study, using the United Nations Index on quality of life - the same index that ranked Canada number one in the world - determined that if Aboriginal people living on reserve were treated as a distinct country they would rank 60th of 170 countries studied. The situation of Aboriginal people living off-reserve was not found to be appreciably better. ${ }^{[8]}$

Given the generally bleak socio-economic conditions on most reserves, many status Indians leave their home communities to live in urban centres where employment and educational opportunities are greater. Once in the cities, these people often settle down and establish families. Current trends are seeing Aboriginal people moving more and more to urban centres. It is estimated that approximately half of the Aboriginal people in Canada now live in urban areas. ${ }^{[9]}$ Although the federal government treats the reserve as the locus for the provision of benefits and services to status Indians, the centrality of the reserve in the life of status Indians is being overcome by a new reality and will be challenged even more in the coming years.

\section{ABORIGINAL OVER-REPRESENTATION IN JAIL}

The over-representation of Aboriginal people in Canada's jails became a matter of public record in the 1980s. In 1988, the Canadian Bar Association published a report by Professor Michael Jackson entitled "Locking Up Natives in Canada." The study revealed that although nationally Aboriginal people made up at most $2 \%$ of the population - they made up $10 \%$ of the inmate population of federal prisons. ${ }^{[10]}$ Provincially the statistics were much bleaker.

What makes these statistics more depressing is that since the report, the situation has worsened. ${ }^{[1]}$ Estimates on how much the incarcerated Aboriginal population would increase in various provinces have proven to be woefully inaccurate - the actual increases have been much larger than estimated. ${ }^{[12]}$ 
The table below looks at Aboriginal over-representation in provincial prisons for 1995/96. A study prepared for the Royal Commission on Aboriginal Peoples was used to determine the percentage of Aboriginal people overall in the provinces and/or regions of Canada. Data on the percentage of Aboriginal people in provincial and/or regional prisons comes from the report, Adult Correctional Services in Canada by the Canadian Centre for Justice Statistics.

In Bridging the Cultural Divide - The Royal Commission on Aboriginal Peoples report on criminal justice- Aboriginal over-representation is described as "injustice personified." ${ }^{[16]}$ The Supreme Court of Canada, in $R v$. Gladue, after reviewing the statistics regarding Aboriginal over-representation, endorsed the first major finding of Bridging the Cultural Divide that:

The Canadian criminal justice system has failed the Aboriginal people of Canada- First Nations, Inuit, and Metis persons, onreserve and off-reserve, urban and rural - in all territorial and governmental jurisdictions. ${ }^{[17]}$

\section{CAUSES OF OVER-REPRESENTATION AND THE NEED FOR ABORIGINAL-SPECIFIC JUSTICE PROGRAMMING}

The fact of Aboriginal over-representation in prison, while shocking, does not inexorably lead to the conclusion that what is required to remedy

Table 1. Aboriginal Over-Representation in Provincial Correctional Facilities

\begin{tabular}{lccc}
\hline & $\begin{array}{c}\text { Col. 2 Aboriginal } \\
\text { People as \% } \\
\text { Age of General } \\
\text { Population }\end{array}$ & $\begin{array}{c}\text { Col. 3 Aboriginal } \\
\text { People as \% } \\
\text { Age of Provincial } \\
\text { Corrections } \\
\text { Population }^{[14]}\end{array}$ & $\begin{array}{c}\text { Col. 4 Level } \\
\text { of Over- } \\
\text { Representation } \\
\text { (col. 3/col. 2) }\end{array}$ \\
\hline $\begin{array}{l}\text { Atlantic (Nfld., N.B., } \\
\quad \text { N.S., P.E.I.) }\end{array}$ & 1.3 & $6^{[15]}$ & 4.6 \\
$\begin{array}{l}\text { Quebec } \\
\text { Ontario }\end{array}$ & 1 & 1 & 1 \\
Manitoba & 1.4 & 8 & 5.7 \\
Saskatchewan & 10.6 & 55 & 5.2 \\
Alberta & 10.5 & 72 & 6.9 \\
British Columbia & 4.9 & 36 & 7.3 \\
Yukon & 3.6 & 17 & 3.7 \\
N.W.T. & 18.2 & 67 & - \\
\hline
\end{tabular}


the problem are Aboriginal-specific justice programs, or, as the Royal Commission recommended, Aboriginal control over criminal justice matters through the exercise of the inherent Aboriginal right to self-government. ${ }^{[18]}$ The fact that members of a visible minority find themselves over-represented in a country's prisons is hardly surprising. In the United States, for example, it is well-known that African-Americans, particularly young AfricanAmerican men, are greatly over-represented in prison. Yet that fact has not caused government commissions to call for the creation of a distinct African-American justice system.

Broadly-speaking, three explanations have been advanced to explain the phenomenon of Aboriginal over-representation. Possible remedial action with regard to over-representation differs depending on the explanation. The three theories are: 1) culture-clash; 2) socio-economic; and 3 ) colonialism. ${ }^{[19]}$ Each theory has merit.

The culture-clash theory starts from the indisputable fact that the Aboriginal worldview and the western liberal worldview are very much at odds, in particular, with respect to the ways in which they deal with socially disruptive behaviour. ${ }^{[20]}$ There are abundant examples of this culture-clash. At its most basic, Aboriginal people traditionally took a more holistic and restorative approach to addressing social conflict. Aboriginal languages had no word for "guilt" or "innocence" and, rather than focusing on punishment, Aboriginal concepts of justice looked to healing and reintegrating the wrong-doer into society. As Ojibway elder Art Solomon put it in his poem The Way It Is In The World Now, December 1974:

We were not perfect but we had no jails and we had no judges or lawyers and no policemen. We had no taxes and we had no wine and no beer and no whiskey.

We had no money,

We had no old people homes,

We had no children's aid society,

We had no crisis centres,

We had no atomic bombs, no hydrogen bombs,

We had no warplanes,

We had no warships,

We had no standing armies.

We honoured our dead, we honoured our people and our children, and we honoured each other. We had self-discipline and a code of moral conduct. We had a philosophy of life based on the Creator and harmony with all of His Creation including this spirit world. And we had our humanity. ${ }^{[21]}$ 
These differences in worldview are not simply historic anomalies. A study on the legal needs of Aboriginal people in Toronto in the 1980s heard from a judge who indicated that Aboriginal accused were the easiest persons to deal with as they readily took responsibility for their offences. ${ }^{[2]}$ Rupert Ross, a Crown Attorney in Kenora, a town in northern Ontario with a large Aboriginal population, describes the many ways this clash manifests itself today in his book Dancing With a Ghost. The culture-clash theory suggests that cultural training and finding ways of accommodating Aboriginal traditional beliefs in the current justice system might address the over-representation issue.

As real as the culture-clash explanation is, it cannot adequately explain the reality of over-representation. If the prime force behind overrepresentation is a culture-clash between Aboriginal and western values, then one would expect that Aboriginal people in jail would be those raised in the traditional ways. Instead, we find the opposite. The Royal Commission on Aboriginal Peoples discovered that at the Prince Albert Penitentiary in Saskatchewan, for example, $95 \%$ of the Aboriginal inmates there had been adopted or placed in foster care. ${ }^{[23]}$ Similar statistics for the Community Council program in Toronto indicate that at least $47 \%$ of those people coming before that program have been adopted or placed in foster care and $40 \%$ had lived in Toronto for over ten years. ${ }^{[24]}$ The culture-clash theory cannot explain why Aboriginal people who have been raised either in the midst of the Canadian mainstream, or raised by non-Aboriginal families, would find themselves disproportionately over-represented in jail. ${ }^{[25]}$

The socio-economic theory attempts to address this issue by suggesting that it is not a clash of cultures that is the determining factor behind overrepresentation, rather it is poverty. Given the generally poor economic conditions of Aboriginal people in Canada, this theory suggests that it is not therefore surprising to find Aboriginal people over-represented in prison. ${ }^{[26]}$ In general, prisons warehouse a disproportionate number of the poor. The theory suggests that an emphasis on making changes to the justice system is misplaced as no amount of change will fundamentally alter the fact that the criminal justice system targets the poor. Rather than looking at justice system reform, the emphasis should be placed on improving the economic situation of Aboriginal people in Canada, both in rural and reserve communities as well as urban centres. As the income levels of Aboriginal people rise, the incarceration rate will drop.

As with the culture-clash theory, there is much to recommend this view. The difficulty with the theory is that it assumes that upward mobility for Aboriginal people is something that can be accomplished if sufficient energy and resources are put towards addressing the issue. While there is certainly an acknowledged need for such programs, the theory fails to 
explain why, in the words of the Royal Commission, Aboriginal people are "poor beyond poverty." ${ }^{27]}$ Why is it that after centuries of contact with non-Aboriginal people, the socio-economic situation of Aboriginal people is declining rather than improving? What are the root causes behind the poverty faced by Aboriginal people?

The third theory of over-representation - colonialism - provides an answer to these questions. The colonialism theory locates the realities of over-representation in the legacy of long-standing government policies explicitly designed to destroy Aboriginal people as a people and to encourage their assimilation into the mainstream of Canada. There is not the space here to describe the innumerable policies that the government of Canada and the provinces adopted over the years to accomplish this end. Volume 1 of the Royal Commission's Final Report - Looking Forward, Looking Back, details these policies in great detail.

The conclusion that colonialism best explains the realities of Aboriginal over-representation is one that has been arrived at by many different commissions, studies and reports. In addition to the Royal Commission, the Aboriginal Justice Inquiry of Manitoba and the Osnaburgh Windigo Justice Report, among others, reached similar conclusions. ${ }^{[28]}$ If over-representation is best explained as arising from the impact of colonialism, a process that is contemporary reality, not merely an historic relic, making changes to the way in which the current system treats Aboriginal accused or working towards the economic improvement of the lives of Aboriginal people, as the first two theories suggest, while important, will not alone bring about substantial change. Instead, Aboriginal people themselves must take the lead in developing responses to justice that are able to address the impacts of colonialism and thus the root causes of criminality among Aboriginal offenders. How that can be done in practice is the focus of the remainder of this paper.

\section{THE COMMUNITY COUNCIL-A CASE STUDY}

Aboriginal Legal Services of Toronto (ALST) was established in 1990. It developed as an outgrowth of the Legal Services Department of the Native Canadian Centre of Toronto. The Department was responsible for the operation of a number of programs working with Aboriginal people in conflict with the law. Following a needs assessment in the late 1980s, it was determined that what was needed in Toronto was a full-service one-stop agency that could address a wide range of legal needs for all Aboriginal people in the city- Indians (status and non-status), Inuit and Metis. ${ }^{[29]}$ During its first year of operation, ALST received funding from the Ontario 
Legal Aid Plan (now Legal Aid Ontario) to operate a legal clinic enabling the agency to offer a broad range of poverty-law related services as well as legal services of particular interest to Aboriginal people.

Toronto is home to the largest Aboriginal community in Canada. The 1991 Aboriginal Census undertaken by Statistics Canada estimated the city's Aboriginal population at over $40,000 .{ }^{[30]}$ Aboriginal service providers put the actual population between 60,000 to 70,000 or even higher. ${ }^{[31]}$ Unlike some other major Canadian cities, there is no one area where Aboriginal people live. While the city is home to many Aboriginal people who hold down jobs and raise healthy families, there is the same level of economic and social dislocation in the Toronto Aboriginal community as elsewhere. For example the Mayor's Homelessness Action Task Force estimated that 8,000 Aboriginal people were, or were at risk of becoming, homeless. ${ }^{[32]}$

In the late 1980s and in the early 1990s the Ministry of the Attorney General in Ontario began an informal, unannounced program of providing funding to Aboriginal communities to allow them to take greater control over criminal justice matters involving members of their community. These alternative justice programs generally took the shape of either sentencing or diversion programs. In sentencing programs, a panel of elders in the community sit with the judge when sentence is handed down and provide input to the court as to the appropriate sentence. Depending on the nature of the program, the elders themselves might speak directly to the offender.

In a diversion program, charges against an accused are either adjourned, stayed or withdrawn in order that the person can participate in the program. Entry into such programs is contingent on the accused person accepting responsibility for the acts that led to the particular charges. In cases where charges are adjourned, successful completion of the diversion program means that the charges are withdrawn by the Crown ${ }^{[33]}$ at a later date.

Diversion and sentencing programs exist because the Canadian criminal justice system gives a great deal of discretion to justice system actors. Thus police have discretion in whether or not to lay a charge, even if they believe a crime has been committed; Crown Attorneys have discretion to have matters dealt with outside of the formal court process, even if they think that a person may be found guilty at trial; and judges have discretion as to how they solicit information to assist with sentencing. ${ }^{[34]}$ The existence of discretion is inherent in the system and is generally exercised at the local level.

In terms of Aboriginal justice initiatives, this high level of discretion means that there is significant flexibility in the ways in which justice can be delivered in communities, depending on the willingness of institutional players to entertain innovative approaches. At the same time, these 
programs cannot be seen in any way as an exercise of the inherent right of Aboriginal self-government, as the Royal Commission on Aboriginal Peoples envisages the process eventually developing. Rather these programs exist at the margins of the justice system. The programs have no absolute right to exist and can be effectively stopped by the transfer or retirement of a key justice official, or the withdrawal of funding by the provincial or federal government to the organization providing the program.

The first two Aboriginal justice programs funded in Ontario were based in the northern reserve communities of Sandy Lake and Attawpiskat. While these programs were funded with little or no fanfare, one of the Board members of ALST was aware that the province was entertaining applications for such initiatives and encouraged the organization to apply for developmental funding to establish a diversion program in Toronto. The program was to be called the Community Council. In its letter to the Ministry of the Attorney General, ALST emphasized that while justice alternatives in reserve communities were important, it was equally important that the province not ignore the needs of urban Aboriginal people. Following the funding application, meetings were held with officials from the Ministry and funding was secured for a one-year period to develop and implement a diversion program for adult Aboriginal offenders in Toronto.

The development phase of the project took eleven months to complete. It included meetings with the Toronto Crown Attorneys Office to establish a protocol for the program; consultation with Aboriginal elders and traditional teachers; consultations with the Aboriginal community in Toronto; and recruitment of Council members. We will look at each aspect of the program in turn.

The Toronto Crown Attorney's Office was very receptive to the project. Discussion with the Crowns did not focus on how a Community Council hearing would function - it was felt that this issue was something solely within ALST's purview - but rather on developing a protocol for the diversion of cases to the program. Over a period of approximately three months, a protocol was established (the protocol is available at ALST's website: http://www.aboriginallegal.ca). The protocol was designed to be as broad and wide-ranging as possible. While all diversions had to be approved by a senior Crown Attorney, no offence nor offender was inherently ineligible for diversion - all cases were to be reviewed by the Crown on their merits. ${ }^{[35]}$ The fact that all Aboriginal offenders were eligible to enter the program meant that people with prior criminal records could access the Council. This was a crucial issue as one of the objects of the program was to reduce recidivism and, obviously, the prime candidates for re-offending are those who have offended before. ${ }^{[36]}$ 
The other significant aspect of the protocol was that, except for exceptional circumstances, charges against the individual would be stayed or withdrawn at the outset of the process. If an individual failed to complete his or her Community Council decision, the matter would not be remitted back to the courts. This aspect of the protocol served two purposes.

First, since charges were not hanging over the head of a person when entering the program, it could not be said that completion of the program could be attributed to the threat of further punishment. The possibility that someone might have to return to court for sentencing if he or she does not complete a diversion program can be seen as a significant variable that may well explain compliance rates. This type of coercion is also antithetical to a program that wishes people to look at their behavior and take the steps to change that behavior. If the motivation for change is not coming from the person but from a desire to escape punishment, then once the program was completed, motivation to continue with whatever initiatives had been begun would be minimal.

Second, the fact that charges were withdrawn at the outset meant that the possibility of net-widening was reduced. Net-widening occurs when a program established to take people out of the criminal justice system actually results in people receiving longer sentences than if they had not entered the program at all. Where a person enters a diversion program and then fails to complete it, the Crown and/or judge may feel that a stiffer penalty than would have been otherwise imposed should be placed on the individual to teach them the lesson that they should not waste opportunities such as diversion. ${ }^{[37]}$

Once the protocol was finalized, a meeting was held with Aboriginal elders and traditional teachers. In the Toronto Aboriginal community, when important decisions are being made, the advice of elders is sought. In this context an elder is a person who is not only advanced in years, but is respected in the community due to her or his wisdom. A traditional teacher is person who may not yet be an elder, but who follows the traditional Aboriginal ways and also imparts that knowledge to others.

In July of 1991, a gathering of approximately 25 elders and traditional teachers took place at the Native Canadian Centre in Toronto. One of the items on the agenda for the meeting was the Community Council program. When ALST approached the elders about the program, it was not simply to ask for advice about how to implement the initiative. Rather, the consultation, as with all consultations on the program, began with the understanding that if the elders and teachers felt that for whatever reason the project should not go ahead, then the project would be stopped. It was felt that consulting people on the assumption that the program would move 
ahead was presumptuous and contemptuous of the consultative process itself.

After hearing a presentation on the project and discussing the matter for a period of time, the elders and teachers agreed in principle that the program was a good idea, and recommended that one of the members of the group arrange for a meeting over a few days with a smaller group of people to discuss the program in more detail. The resulting meeting took place in August on Birch Island, in northern Ontario, near Sudbury.

At the Birch Island gathering, the focus of the discussion was to establish the broad framework for the Community Council program. At the gathering, elders and traditional teachers were asked to provide guidance on issues such as what qualities should those who serve as Council members possess and how should potential diversion candidates for the program be selected (a summary of the Birch Island gathering can be found on the ALST web site noted earlier).

The gathering laid the foundation for the program. In response to the questions posed above, it was felt that Council members should be recruited on the basis of their ability to bring respect and kindness towards victims and offenders in the process. With regard to selecting people for admission to the program, the gathering said that there should be no selection criteria used at all. Rather, all people eligible for entry in the program should be able to access it. The fact that, for example, a person might have prior convictions does not say anything about how the person might react if treated with kindness and respect. Prior convictions merely show what we already know, that the current system has little relevance to Aboriginal people.

In this regard, the gathering also stated that people who have come before the Council and completed their decision should be able to enter the program again if they are charged with a subsequent offence. Returning before the Council will likely engender a mixture of both pride and shame in people. They will feel pride in that they were able to complete the decision that they had agreed to, and, at the same time, they will also likely feel shame that they are once again before the Council - that they were not truly able to lead the type of life that they wanted to lead. This combination of feelings might well make the person more receptive to thinking about further changes in their lives. Change, the gathering pointed out, is not something that happens overnight, it is a process, a path, and the journey on that path is long and difficult - it should not be assumed that just because a person slips on that journey that they are no longer worthy of time and attention.

Following the Birch Island gathering, meetings were held in Toronto with the Aboriginal community to discuss how, in practice, the Community 
Council might function in that city. The fact that the project now had the approval of elders and traditional teachers provided it with a great deal of credibility.

Consultation with a diverse scattered population in a city like Toronto is challenging. Two meetings were held with representatives of Aboriginal social service organizations. There are over 40 such organizations in Toronto representing a wide range of issues and concerns and generally serving all Aboriginal people. In many ways this group served as somewhat of a microcosm of the entire community. In addition to these meetings, ALST staff were interviewed on radio programs, both general interest and Aboriginal-specific, and also gave a presentation at the annual general meeting of the Native Canadian Centre of Toronto, the largest multipurpose Aboriginal agency in Toronto. ALST staff also spoke to the Boards of Directors of Aboriginal agencies when requested.

These meetings, particularly the two with social service agencies, were an opportunity to discuss frankly what concerns existed with regard to the program. Two issues emerged strongly from these meetings: one, the taking on of cases of family violence; and two, what to do with individuals who did not comply with their Council decision.

With regard to family violence, strong concern was expressed at the meetings that the project had not fully considered how to protect the interests of women who were the victims of family violence. It was felt that family violence cases posed particular challenges to diversion and that the Council process had not yet determined adequately how to address these challenges. As a result, it was felt that family violence cases should not be diverted to the Council. That direction was accepted and family violence cases were not accepted for diversion. ${ }^{[38]}$

The discussion regarding what to do with those who did not comply with Council decisions was quite lively and required two meetings until a consensus was reached. Given that those who did not comply with their Council hearings were not going to go back before the courts, the question was raised about the consequences such individuals should face for noncompliance. The only sanction envisioned in the protocol negotiated with the Toronto Crowns Office for a person who failed to comply with their Community Council decision was that they would not be able to enter the diversion program again if they were arrested. Discussion at the meetings focused on whether this was a sufficient consequence.

One suggestion advanced was to look at a modern type of banishment. Traditionally in Aboriginal communities in Ontario and elsewhere, people who repeatedly refused to abide by the norms of their community were eventually banished from the community. ${ }^{[39]}$ The period of banishment might vary from a few days to a lifetime ban. In that light, it was suggested 
that people who did not comply with their Council decision be essentially banished from Aboriginal organizations in the city. This would be accomplished by publicizing the names of those who did not comply and circulating them around to the various agencies. This process would be a form of shaming - shaming also being a traditional form of order maintenance in Aboriginal communities. ${ }^{[40]}$

Those who were concerned with the banishment approach had two major objections. First, some Aboriginal agencies had a mandate, either contractually or as part of their mission, to serve all Aboriginal people, refusing service to people in need would violate those commitments. Second, it was felt that many of the people in the Toronto Aboriginal community, particularly those who came before the courts, had already been effectively banished from Aboriginal communities. Forms of effective banishment included adoption and foster care and violence or inter-personal conflicts on reserve. For these marginalized people, what was needed was not finding additional ways to exclude them, but rather, finding ways to bring them into the community. At the end of the day, the arguments against banishment prevailed and the consequence for those who did not comply with their Council decision remained only that they could not enter the program again if arrested on a subsequent charge.

The final stage of the implementation process was the selection of Council members. This stage proved to be very challenging. As the name of the program suggests, the Community Council was envisioned as a program that belonged to the entire Aboriginal community in Toronto, not simply to ALST where it was housed and where operational responsibility lay. Given that vision, it seemed antithetical to have staff at ALST appoint or select those who would be Council members. Eventually, it was decided that the best way to select Council members was to go to the community itself. Again, community agencies were used as proxies for the entire community. The Boards of Directors of Aboriginal agencies were approached, first by letter and then in telephone or in person, to nominate individuals to serve as Council members. In order to provide some guidance to the Boards, the summary of the Birch Island gathering was provided.

After the names of nominees were received, ALST contacted the individuals to ask if they were interested in being a Council member. Those who indicated that they had such an interest were invited to a weekend gathering at the Native Canadian Centre to discuss the project in February, 1992. Eighteen potential Council members attended the meeting. All of those attending were told that they would not be asked to make a commitment to the project until the discussion of how the project would operate concluded on Sunday. At that time, if there was not sufficient interest in the project, there would be no additional recruitment steps taken. 
If those who the community felt should be Council members were not comfortable in that role, then ALST would have to rethink the project or simply abandon it for a period of time.

Discussions over the weekend focused on how the Council process would work, an examination of the protocol, and a review of the various consultations. On Sunday, all of the eighteen people who attended the gathering as potential Council nominees agreed to serve as Council members and the project moved to hearing cases.

\section{HOW THE PROCESS EVOLVES}

The reader will note that little has been said to this point in this paper about how the actual hearing process operates in the Community Council. While some might see the determination of the form of the hearing as one of the first matters that must be addressed when an alternative justice program is developed, the Community Council took a different view. While all hearings follow generally a set process, the process for hearings has evolved over time as Council members gained more experience and looked to find new and innovative ways of reaching out to clients.

The basic form of a hearing is simple. Schedules are sent out to Council members a few months in advance indicating when they will be sitting on a hearing. Three Council members are scheduled for an afternoon or evening session and each session deals with two or three cases. Prior to hearing the cases, the Council members meet for an hour before the hearings are scheduled to review the files of the individuals coming before the Council. The files contain information on the specific offence for which the individual was charged, a list of prior convictions of the individual (if any) and a two page information form filled out by an ALST staffperson following an interview with the client after the diversion.

Council members are representative of the Aboriginal community in Toronto in that they represent many different nations and traditions. ${ }^{[1]}$ While a Council members could be chosen for specific hearings based on the tribe or affiliation of the person coming before the Council, that has not emerged as an issue. For the most part, most of the people coming before the Council are not particularly connected to an Aboriginal community either in the city or elsewhere. For many of these people, they have only a vague sense of what it is to be an Aboriginal person outside of the negative stereotypes they might have been exposed to.

Prior to the client entering the hearing room, an ALST staff person meets with the client to answer any questions the person may have about the process. Although the process will have been explained to the client 
previously, it is not uncommon for a person to have additional questions prior to the hearing.

The hearing begins with Council members introducing themselves to the client and the client introducing him or herself to the Council. These introductions are in no way perfunctory. Council members often take this opportunity to tell the client a bit about themselves and why they are a Council member. Introductions of the Council members hearing a matter have taken ten to twenty minutes.

The hearing itself consists of Council members asking questions of the client. Those questions can focus on the offence itself, or be more wideranging - exploring the client's family life, substance abuse history, etc. There is no formal process for questioning and any Council member may ask any question at any time. In keeping with the direction of the elders and traditional teachers to treat people with kindness and respect, the questioning process is not a grilling where clients are asked a series of difficult questions in rapid-fire style. Rather, the client is given an opportunity to say whatever he or she feels comfortable saying. If the client does not wish to talk about a certain subject, the Council will move on, although they may return to the matter later.

In addition to questions, there is a great deal of give and take in a hearing. Council members often share their experiences with clients as a way of making points. Many of the Council members have a personal understanding of the impact of addictions, the criminal justice process, violence etc. In a very real sense, Council members understand the realities of the clients who come before them. It is not surprising in a Council hearing to have clients discuss matters that they have never spoken of to anyone else. One reason for the openness of clients in a hearing is that the Council follows a strict policy of confidentiality.

At some point in the hearing, the client is invariably asked what he or she thinks the Council should do with the case - what sort of disposition would be appropriate. In most cases, the client suggests what he or she thinks will help in preventing a recurrence of the criminal behavior.

When Council members are satisfied that they have all the information they can reasonably expect, the client is asked to leave the room and the Council makes a decision in the case. As the focus of a hearing is on the individual, decisions in each case are unique. There are no precedents nor are there any guidelines that must be followed stating that those who are charged with a particular offence receive a particular decision. Two people charged with exactly the same offence, coming before the some Council members on the same day, may end up with radically different decisions. This development is not surprising because each individual coming before the Council is unique. 
Once the Council has reached consensus on a decision, the client is invited back to the room and the decision is read to the client. A discussion then takes place about whether the client is willing to accept the decision. If the client has some reservations about the decision, it will be discussed in more detail and may be changed. If the client is content with the decision, he or she signs two copies - one remains on file at ALST the other is given to the client.

Council dispositions can cover a wide range of responses. Among the more common dispositions are counseling - traditional or non-traditional, attendance at self-help groups, community service, restitution, seeking employment or educational upgrading, letters of apologies, continued contact with ALST and location restrictions. A particular disposition will usually include a number of responses.

The first Community Council hearing was held in March, 1992. In the ensuing years, the basic form of a Council hearing has remained the same but significant variations have emerged to meet the needs of clients and Council members. These variations are developed by Council members in particular cases. If the changes are positive, they are adopted in other hearings. All Council members meet together at least twice a year to discuss the project and to share their questions, concerns and ideas about improving the process. ALST staff involved in the project also regularly provide information to Council members as to the recent innovations other Council members have developed.

One of the challenges the Council faced initially was resisting the pull of the formal legal process in terms of steering the form of the Council hearing. For example, the first few Council hearings were held around a rectangular table where the Council members sat on one side, the client on the other and the staff person on the side taking notes. After a few hearings, however, a Council member asked why this format was being followed and subsequent hearings have all taken place around a circular or oblong table or in circle without a table.

More recent innovations to the hearing process have seen Council members ask clients to return before them at regular intervals in order that the Council may discuss their progress with them. These meetings allow the Council members to follow up with clients and encourage them in the work that they are doing.

In addition to the volunteer members of the Council, ALST staff work with clients on an ongoing basis following their hearing to assist them in complying with their decisions. Decisions of the Council are framed generally - indicating, for example, the type of counseling a client should receive or setting out the number of volunteer hours the person should do. Determining the specifics of the decision is a matter between ALST staff and the client. 


\section{THE COMMUNITY COUNCIL MODEL}

In developing the Community Council, little reliance was placed on what other justice related diversion projects were doing. One reason for this is that in 1992, when the hearings began, there were few models available to look at for reference. The Council was the first urban Aboriginal alternative justice project in Canada and was thus in many ways unique.

While the Council has similarities with many other types of programs, it also differs from them as well. Council members control the process, and, while individuals are invited to bring support people with them, those people may or may not speak to the Council and may or may not be present during the entire Council hearing, depending on the feelings of the Council members. The Council's experience has been that not everyone who might accompany a client to a hearing as a support person is truly a support; they may, in fact, be more of the problem than the solution.

Prior to the diversion of a violent offence, the victim of the offence is contacted to determine their feelings towards the matter being diverted. As ultimately it is the Crown that has the final decision on the matter, victims do not have a veto over the process, although any reservations regarding diversion will usually mean that the matter will not be diverted. In cases where the offence is a property offence, victims are generally not contacted. The Community Council is not a victim-offender reconciliation program (VORP). Even where victims are contacted and consent to diversion, they do not necessarily participate in the process. The main reason for this is that most victims do not wish to meet the person who caused them harm. While ALST staff encourage victims to attend and participate in hearings, most decline to do so. In a VORP, the refusal of the victim to participate in the program means that the matter remains in the court system. This is not the case with the Community Council.

In those cases where the victim does attend, the Council does not attempt to mediate the dispute between the parties, rather they hear both sides and then come to a decision. While the parties have a role in determining the decision, ultimately it is arrived at by the Council members themselves. As a result, the program is not a mediation type program.

Perhaps the category that best describes the Council is "Aboriginal alternative justice program." This term encompasses a wide range of programs that address criminal behavior in many different ways. What these programs have in common is that they are based on Aboriginal concepts of justice and respond to the particular needs of the community.

Because the Council does not easily fit into established categories for alternative or restorative justice initiatives, and because it has been in operation for nearly a decade, Council members express little interest in 
training opportunities that focus on dispute resolution techniques. Training for Council members is regularly provided and the subject matter of the training is usually suggested by Council members themselves. For example, at the most recent training weekend, topics included: working with clients with mental health problems; the impact of adoption on Aboriginal people; how trauma manifests itself; and teachings from an elder.

\section{CONCLUSIONS}

The Community Council is one of the longest-running Aboriginal alternative justice programs in Canada. It has been the subject of newspaper, magazine, radio and television coverage. In its report on justice, the Royal Commission on Aboriginal Peoples featured the Community Council as one of two case studies. While it is difficult to generalize what factors are necessary for the creation of a successful alternative justice program, the experience of the Community Council suggests three matters are crucial: 1) the need for a project development phase; 2) the necessity for projects to develop their own approaches to the resolution of disputes; and 3) community accountability.

Unfortunately, not all Aboriginal justice projects have succeeded quite as well as the Community Council. In Ontario alone, three projects that were funded at some point over the past 10 years are no longer in operation. The reason why some programs succeed and others fail is a subject worthy of a paper of its own. One important factor, however, is clearly the need for a project development stage to allow the program to develop to meet the needs of the local community. Where justice projects do not have the opportunity for such development, their chances of success are more limited. This conclusion has been supported by a number of studies on such programs. $^{[42]}$

One of the reasons that a project development phase is so crucial is that it allows those involved in the project to determine how they wish to address matters in their own community. The last few years have seen an explosion in models of alternative dispute resolution. There are many courses that one can take to learn about techniques and practices that can be used in such programs. While there is nothing wrong with learning about mediation, or victim-offender reconciliation, or family group conferencing, it is important that communities see these as potential options rather than as templates. Imposing alternative justice models will not work in the long run. Communities themselves must determine what issues they wish to address and how they wish to address them. 
The strength of a community justice approach is in the community itself. The resources the community can provide to the project, both in terms of social service agencies and volunteers are vital. The hardest working volunteers in the world will have difficulty making a big difference in the lives of those coming before them if the community has no resources for people who, for example, have been the victims of childhood abuse or who have addiction issues.

At the same time, care must be taken to ensure that the process does not become too professionalized. One of the great strengths of the Community Council is that it relies on volunteers who are taking time out of their lives to meet with clients, most of whom they have never met before. For many clients, prior to a Council hearing, they had never met anyone who was interested in their lives who was not being paid for that interest be it a doctor, an addictions worker, or a probation officer. While the Community Council could not operate without the staff who support the program and meet regularly with clients after their hearings, it is the Council hearing itself that is the catalyst for change. Those who volunteer in this difficult work must be given the opportunity to fashion a process that they find comfortable. It makes no sense to force people into roles that may not be relevant to them or to the people who are appearing before them. There is a danger that professionalization of dispute resolution will mean that volunteers will feel inadequate in doing the work that relies so much on them. Historically in Aboriginal communities it was the community as a whole that worked together to maintain order - as Art Solomon's poem stated "we had no judges or lawyers and no policemen." Strengthening Aboriginal communities means empowering volunteers to take on the work that they need to do in a way that works for them.

Finally, it is vital that alternative justice programs be accountable to the community. In the case of the Community Council this means community consultations that are meaningful and where the concerns of people are heard. It means that community members are not just asked "What do you think of this justice project model?" but, rather, are given input into the preliminary question "Do you want an alternative justice program in the community and what should it look like?" As the Community Council has matured, consultation means going back to these groups to discuss ways that the program might expand its focus.

Community accountability and acceptance is not only important in the development of a program, it is important for the program's long term viability as well. No person or program is perfect. Mistakes will be made. Where there is accountability and where the community can truly feel that the project belongs to them, then these inevitable bumps in the road can be addressed for what they are, problems that can be resolved. 


\section{REFERENCES}

1. Jonathan Rudin is the Program Director at Aboriginal Legal Services of Toronto (ALST). I should make it clear that my interest and involvement in the Community Council program, the focus of this paper, is not strictly academic; it is in fact extremely participatory. I have been involved from the outset of the program in all aspects of its development and delivery. I am therefore drawing extensively on my recollections and understanding of the decisions made during the project's initial phases. In addition to working at ALST, I also teach in the Social Science Department at York University. I can be reached at jrudin@yorku.ca. The opinions expressed in this paper are those of the author.

2. The word Aboriginal is capitalized throughout the paper unless it is part of a direct quote.

3. Rv. Sparrow. [1990], 1 S.C.R. 1075.

4. Rv. Van der Peet. [1996], 2 S.C.R. 507.

5. Mitchell v. Minister of National Revenue [2001], 1 S.C.R. 33.

6. Indians are further divided by the federal government as those having status and those not having status. It is the federal government who determines, under the provisions of The Indian Act, who is or is not entitled to Indian status.

7. Royal Commission on Aboriginal Peoples, Looking Forward - Looking Back; Minister of Supply and Services: Ottawa, 1996; Vol. 1, 15-16.

8. Canadian Human Rights Commission, Annual Report; Canadian Human Rights Commission: Ottawa, 1998.

9. Royal Commission on Aboriginal Peoples, Perspectives and Reality; Ministry of Supply and Services: Ottawa, 1996; Vol. 4, 519.

10. In Canada, those people sent to jail for a period of two years or more serve their time in federal prisons. Those serving sentences under two years are sent to provincial institutions.

11. Royal Commission on Aboriginal Peoples, Bridging the Cultural Divide; Ministry of Supply and Services: Ottawa, 1996; 28-33.

12. Hylton, J. Financing Aboriginal Justice Systems. In Continuing Poundmaker and Riel's Quest; Gosse, R., Henderson, J.Y., Carter, R., Eds.; Purich Publishing: Saskatoon, 1994; 115. Justice On Trial: Report of the Task Force on the Criminal Justice System and Its Impact on the Indian and Metis People of Alberta; Government of Alberta: Edmonton, 1991; 1, 17.

13. Figures regarding Aboriginal People as a percentage of the general population in 1996, Looking Forward - Looking Back; 22. 
14. Figures regarding Aboriginal people as percentage of provincial prison population from Canadian Centre for Justice Statistics, Adult Correctional Services in Canada; Centre for Justice Statistics, Statistics Canada: Ottawa, 1996; 30.

15. The prison percentage for the Atlantic region is an approximation. Royal Commission on Aboriginal Peoples population figures group all four Atlantic provinces together, Centre for Justice Statistics data break them out by province - the specific figures are Newfoundland $7 \%$; Prince Edward Island - 3\%; Nova Scotia - 4\%; New Brunswick - 6\%.

16. Bridging the Cultural Divide, 28.

17. Ibid; 309; $R$ v. Gladue 133 C C.C. (3d) 385.

18. Ibid; 224 .

19. Ibid; $39-53$.

20. Ibid; Rudin, J., Russell, D. Native Alternative Dispute Resolution Systems: The Canadian Future In Light of the American Past; Ontario Native Council on Justice: Toronto, 1993; 38-42; Dockstator, M. Toward An Understanding of Native Criminality; Osgoode Hall Law School: Toronto, 1984; 17.

21. Solomon, A. Songs for the People; NC Press: Toronto, 1990; 70.

22. Obonsawin Irwin Consulting, Report to the Native Canadian Centre of Toronto - Legal Services Needs Assessment; Native Canadian Centre of Toronto: Toronto, 1989.

23. Bridging the Cultural Divide, 129.

24. Aboriginal Legal Services of Toronto, Statistical Report for the Period July - September, 2000; Aboriginal Legal Services of Toronto: Toronto, 2000.

25. Rudin, J. Aboriginal Self-Government and Justice. In Aboriginal SelfGovernment in Canada, 2nd Ed.; Hylton, J., Ed., Purich Publishing: Saskatoon, 1999; 210.

26. Obonsawin Irwin Consulting, Future Aboriginal Justice Project Development Needs: An Addendum to the Sandy Lake and Attawapiskat First Nations Justice Project Evaluation Reports; Ministry of the Attorney General: Toronto, 1992.

27. Bridging the Cultural Divide, 46.

28. Ibid, 52; Royal Commission on Aboriginal Peoples, Choosing Life, Special Report on Suicide Among Aboriginal People; Ministry of Supply and Services: Ottawa, 1995; Report of the Aboriginal Justice Inquiry of Manitoba; Government of Manitoba: Winnipeg, 1991; Vol. 1, 91; Report of the Osnaburgh/Windigo Tribal Council Justice Review Committee, prepared for the Attorney General (Ontario) and 
Minister Responsible for Native Affairs and the Solicitor General (Ontario); Government of Ontario: Toronto, 1990; 4-6.

29. Obonsawin Irwin; Report to the Native Canadian Centre of Toronto.

30. Statistics Canada, 1991 Aboriginal Census; Statistics Canada: Ottawa, $1993 ; 15$.

31. While there is no specific breakdown of the Toronto Aboriginal population, the majority of Aboriginal people in the city are Indianstatus or non-status. There are not many Inuit people in southern Canada as a whole and therefore they make up a small proportion of the Toronto community.

32. Report of the Mayor's Homelessness Action Task Force, Taking Responsibility for Homelessness - An Action Plan for Toronto; City of Toronto: Toronto, 1999; 66.

33. The term "Crown" and "Crown Attorney" refer to the individual who prosecutes cases on behalf of the state. In the United States, the District Attorney is equivalent to the Crown Attorney.

34. Rudin, Aboriginal Self-Government and Justice, 214.

35. While in theory the program can take all types of offences, the bulk of the offences committed by those coming before the Council involve property crimes, assaults, robbery, prostitution, theft and what are broadly termed offences against the administration of justice - failure to attend court and failure to comply with a bail or probation conditions. While most assaults do not involve serious physical harm, cases have been diverted where the victim did require hospitalization. While most theft charges also deal with relatively small sums, cases involving goods with a value of over $\$ 10,000$ or more have also been diverted. Given the fact that most of those coming before the Council have prior criminal records, the most likely disposition of matters had they not been diverted would have been a jail sentence.

36. Two studies of the program completed in 2000 reached somewhat different conclusions regarding the extent to which the program reduced recidivism. An outcomes evaluation of the program undertaken by Jane Campbell and Associates could not conclude that the program led to a reduction in recidivism but did find that there was a decline in the number of offences committed by individuals following attendance at a Council hearing (http://www.aboriginallegal.ca). An unpublished study by the federal Department of Justice concluded that the program led to a statistically significant reduction in recidivism of approximately $30 \%$. The Department of Justice study looked at clients over a longer time period than the Campbell study. The broader issue of how much weight and/or relevance to place on such studies, both in 
terms of their ability to accurately track recidivism and the relevance of such data in any event, is a topic worthy of a paper in itself.

37. Van Ness, D.; Carlson, D.; Crawford, T.; Strong, K. Restorative Justice - Theory; Justice Fellowship: Washington, D.C., 1989; 41-42.

38. After the Council began hearing cases the Ministry of the Attorney General issued broad guidelines expressly prohibited the diversion of cases of family violence to any type of alternative justice program Aboriginal or non-Aboriginal. In recent years, that absolute ban has been lifted as various special programs for family violence cases have been developed. ALST has been involved in a series of discussions with a broad range of Aboriginal social service agencies serving, among others, women and children, to discuss how the program might be able to take on such cases. While a draft protocol for such cases has been developed, it has not yet been implemented.

39. Coyle, M. Traditional Indian Justice in Ontario: A Role For the Present Osgoode Hall Law School Journal 1986, 24, 611.

40. Ibid, 625 .

41. There are no Inuit Council members although an Inuit elder does attend Council hearings when he is in the city.

42. Bridging the Cultural Divide, 169; Future Aboriginal Justice Project Development Needs, 17; Moyer, S., Axon, L. An Implementation Evaluation of the Native Community Council Project of the Aboriginal Legal Services of Toronto; Ministry of the Attorney General: Toronto, 1993; 23, 29, 30 . 